\title{
Study on Financial Securities Information and Related Research
}

\author{
Gong Chao \\ Jilin business and technology college , NO.1666 Kalunhu Str. Changchun Jiutai economic development zone. \\ Changchun City, JiLin PROV. China, 130507 \\ cmz2997@sian.com
}

Keywords: Financial Securities, Information Search, Related Search

\begin{abstract}
Any changes in the stock market, whether at the macro level or at the micro level, it will cause changes in the securities market. Information for the securities market is very important to invest and timely access to effective information will be able to get the commanding heights. This paper is mainly on financial securities investment information and related research, including how to obtain online securities investment information and several important securities website.
\end{abstract}

\section{Introduction}

The important weapon of securities investors is information, information is the key to invest in securities market, how to obtain valuable financial information, which financial securities information is effective, how to obtain effective securities on the network information is every securities investors are The question of concern. This paper is mainly financial securities investment information and related research, focusing on how to get valuable online securities investment information. Major policies include tax breaks, increased information, interest rate changes, incentive investments, and domestic investment corrections. Second, the issuance of securities-related companies, such as the turnover of each month, a quarterly profit and loss statement, the flow of funds and income statements, the decision of the shareholders meeting. Third, the general means of production statistics. Analysis of these data can be the industry's production and operation to understand. Fourth, the trade statistics of the relevant information, you can understand the trade volume within a month and out of the super, into the ultra-the situation for the impact of the currency exchange rate, trade and super into the stock market also has an impact, is to be analyzed information The Fifth, non-economic factors. For example, political risk, local war and so should be of concern. Sixth, the stock market which is also effective information, every day the stock market opening price, closing price, stock market turnover, up or down, ups and downs of the index and the stock changes and other conditions should be understood.

\section{Information Sources of Financial Securities}

Our securities laws require securities to provide the necessary materials when the securities are issued, including the company's business conditions, expert opinions, the company's major equipment and business, the company's shareholding structure, the company's financial situation. Generally speaking, the securities regulatory agency will regularly publish the following information: First, the type of stock listed companies, each stock in the year the lowest price and the highest price. Second, the listed company turnover the statistical table, the main content of the year included in the operating income, tax profits before the company. Third, the securities trading information, the main content is last month's securities memorabilia, the issuance of securities and so on. Fourth, the securities statistics, it is mainly securities issuance and securities transactions and other relevant statistical information.

In addition to publicly available information, investors should attach great importance to information obtained from private channels, such as the company's important information, which is 
often more real and reliable than the public information. If information on these private sources is available in advance, relative to other investors are more in a favorable position. You can get information on financial securities investment from the Internet, many companies are online to disclose their own statements and many companies have a dedicated website to publish financial securities information, including the industry's overall report, market reports, the Internet as a source of information an important channel.

\section{Method to Use Information Resources on Financial Securities on the Internet}

At present, many well-known database retrieval systems are available for Internet users to retrieve, commonly used Dialog system, Wanfang database resource system, CNKI China Journal Network database and so on. Most of these systems need to be registered to establish a legitimate account, but compared with the traditional line of online search, the cost of its much cheaper. Dialog (http: // www.dialog.com) as the world's largest online retrieval system, which contains a very comprehensive content, including the basic aspects of each subject literature and factual information, especially in the literature is widely characterized. Compared with other professional categories of documents, including the financial information contained in the document is characterized by rich information, the company's statements, statistics, annual reports can be obtained in the relevant documents. In Dialog, there are 42 documents related to financial securities information, but the range of documents is different.

(Http: // www.wanfangdata.com.cn) It includes a large number of domestic business database, and online to provide a large number of news, research and reference class information. Among them, Chinese enterprises, companies and product databases have been Dialog and other online search system included, into the international market. China Knowledge Base Project (http: // www.cnki.net) is another big step in the construction of online information resources in China. It contains four series of self-produced journals, newspapers, conference papers and dissertations, and gradually formed, including business Information, including a comprehensive information resource system. Among them, most of the financial and securities information databases involved are research classes and reference classes.

Electronic media mainly includes online newspapers and newspapers online version, radio and television sites and some special news information website. Electronic newspapers and radio and television websites generally provide news of financial securities information, and electronic journals to provide the majority of research and reference class of financial securities information. (Www.cs.com.cn), which is the first in 1995 in the country launched a professional securities newspaper online version, is currently a larger impact of the site. Content of financial news, securities market dynamics, listed companies reported that the stock market, investment funds and so on. (Shanghai Stock Exchange), Shanghai Securities News is the first securities professional newspaper, founded in June 10, 1991 (Shanghai Stock Exchange), Shanghai Securities News is the first securities professional newspaper, founded in June 10, 1991 , July 1 officially published August 11, 1995 from the newspaper by the Xinhua News Agency Shanghai Branch; Securities Times Online (www.securitiestime.com.cn), Securities Times has more than 200 journalists, all securities website from the most information on the site, it is updated every day more than 500 news, the use of institutional investment channels brought together dozens of brokers nationwide research report; People's Daily Online (www.peopledaily.com.cn), the site's biggest feature is Contains a lot of political and economic authority of the news, for the stock market analysis has a reference role.

\section{Online Chinese Financial Securities Information Problems}

Although the current online Chinese information is not rich, the financial information in the online Chinese information has accounted for the majority. Nevertheless, online Chinese financial securities information is still a lot of problems, mainly in the following areas:

According to CNNIC calendar year statistics, that the online financial securities information can not meet the demand for the number of people gradually increased, especially since 2000, the 
number increased more rapidly. People demand trends shown in Figure 3. It can be seen that the online Chinese financial securities information is far from meeting the needs of people, and this contradiction between supply and demand is increasing trend.

Information distribution is not balanced. First of all, the nature of the site is not balanced distribution of the main body. The survey results show that Chinese financial securities information by professional personal websites and commercial sites to provide, these two sites accounted for $98 \%$ of the total number of sites. And government websites and educational sites are few. This also shows that Chinese financial securities website is not yet mature. Second, the content distribution of the site is not balanced. At present online Chinese financial securities information is mainly distributed in the general professional website, usually that the content of the general class site is relatively mixed, all kinds of information mixed in such sites, the division of labor is not obvious, the characteristics are not prominent, will affect the long-term development of the site.

In order to facilitate the study, we divided the online financial securities information into news, fact, research, reference, general, corresponding, and financial securities information related to the site is also divided into five categories, the main site to provide the corresponding The information. This kind of division has some truth, but from the actual situation of our website, the fact class, the research class, the reference class is obvious, the news class and the network media cross, the fact class is mixed in the general class, belongs to the general class Comprehensive category) more, all kinds of boundaries is not very obvious. According to our survey, the general category of websites in the financial securities professional website accounted for $70 \%$, this "big and complete", "small and full" phenomenon so that users can not selectively select the site in order to obtain certain type information. In addition, the individual information provided by the site is also more dispersed, not a system. (4) Content cross-repeat. Online Chinese financial securities information cross-repeated phenomenon is also more serious, and sometimes message even in almost all sites are appearing. The reason for this situation is multifaceted, in which the ease of replication of network information, the imperfect law, the lack of information channels, and the monotony of information sources are important reasons. Of course, cross-duplication has both advantages and disadvantages, on the one hand where the user can get the same information on the site, to facilitate the user; but on the other hand this cross-repeated low level of possibility is relatively large, and may cause other aspects of the blank.

\section{The Improvement of Organization and Management of Financial Securities in China}

As soon as possible to develop online financial securities information unified classification. Although our country has "in the law", "information law" and other molding classification system, but they are largely for the printed literature, the network information has many places do not apply. Compared with the traditional information resources, network information resources with a large number, many types, dynamic and so on. In the information content, the emerging disciplines of technology, business, entertainment, the number of more, and the traditional knowledge of the categories of information resources is relatively small. In addition, there is no authority to require online information is also organized by the traditional classification system. However, the proliferation of network information resources require a new, suitable for dealing with the classification of network resources framework, so that all kinds of information into their class, each have their own, so that the station "law can be", so that users can be classified. Fan online financial securities information release behavior, establish and improve the corresponding legal norms. At present, Chinese online financial securities have different sources of information, in which copy and copy, resulting in the duplication of information surge, the authority to reduce the station to the station and investors to bring some losses.

The establishment of a comprehensive standardize network of financial securities information navigation system. In view of the situation that Chinese financial and securities websites are isolated from each other, the lack of contact and the corresponding network navigation and search engine imperfect situation, we need to establish a comprehensive and standardized network financial securities information navigation system so that each website and every information is 
included in this System. Through this navigation system we achieve all online Chinese financial securities information of the orderly organization, multi-channel search and efficient use.

Development site features, improve network services. Features are the basis of existence and convenient service is the biggest feature of the network. Only the development of distinctive, high-quality services, the site has its existence and the survival of the existence of the prerequisites. Chinese financial securities website generally lack of characteristics, content, style is very similar, do not change the status quo, still can not escape the fate of the site closed.

\section{Conclusion}

Financial securities market changes, how to obtain valuable financial securities information is a high priority for every investor, this paper mainly analyzes what information for the effective financial securities, financial securities, the source of fine information, and several common financial Securities investment website.

\section{References}

[1] Gong Fang. Xinhua Finance of Chinese enterprises and financial securities database [J]. Digital Library Forum. 2006 (03)

[2] Ma Dechao. Analysis of Chinese financial securities status and countermeasures[J]. Management Manager. 2016 (17)

[3] Ruan Jianhai. Status and acquisition of financial securities information resources on the Internet[J]. Journal of Southwest China Normal University (Natural Science Edition). 2002 (01)

[4] Wang Hua. Chinese financial securities development of the relevant inquiry[J]. Modern Economic Information. 2014 (05)

[5] Dong Dong, Cao Duan. Exploration and Practice of Experimental Teaching of Financial Securities in Information Age[J]. Journal of Experimental Science and Technology. 2007 (01)

[6] Rong Weijie. Method and method of developing online financial securities information resources[J]. Modern Information. 2003 (01)

[7] Liu Jinhui. Ten years of lonely casting financial Huangpu - China Youth Financial Securities Training Center Director Han Shijun[J]. Digital wealth. 2003 (09) 